Social drugs

\section{Social drug policies for sport}

M Turner, P McCrory

\section{Athletes who test positive for social drugs should be managed differently from those who test positive for performance enhancing drugs}

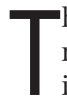
he use and abuse of social drugs is now widespread in society, and there is no evidence that sport is immune. UK Government statistics quoted in the Sunday Observer (21 April 2002) put the usage in the 16-18 year old age group at about $40 \%$ when individuals were asked

Table 1 Results of UK Sport drug testing in the United Kingdom (1988-2001): Anti-Doping Report 2000/200 of UKSport (info@uksport.gov.uk)

\begin{tabular}{lll}
\hline Category & Number & $\%$ of total \\
\hline Stimulants & 410 & 42.4 \\
Narcotic analgesics & 60 & 6.2 \\
Anabolic agents & 244 & 25.2 \\
Diuretics & 30 & 3.1 \\
$\beta$ Blockers & 11 & 1.1 \\
Peptide hormones & 6 & 0.6 \\
Doping methods & 0 & 0.0 \\
Marijuana & 67 & 6.9 \\
Alcohol & 7 & 0.7 \\
Hypnotic sedatives & 2 & 0.2 \\
Refusals & 131 & 13.5 \\
Total & 968 & 100.0 \\
\hline
\end{tabular}

"have you taken any recreational drugs in the last 12 months?"

In a recent statement, a retired Australian footballer claimed that $80 \%$ of elite footballers in Australia had used or been offered recreational drugs. This statement received an extraordinary amount of media attention, and other commentators and footballers claimed that the figure was closer to $30 \%$. What this highlighted was that these issues are extremely common and, interestingly, mostly noted in younger $(<20$ year old $)$ footballers.

The International Olympic Committee (IOC) prohibits some of the products commonly found on the "club scene", because they are perceived to be performance enhancing, but most so called "recreational" drugs do not fall into this category. Sporting bodies that limit their testing programme to the IOC prohibited list alone will therefore not be aware of players who use or abuse these drugs on a regular basis.

\section{BRINGING SPORT INTO DISREPUTE}

The IOC first introduced the monitoring of cannabinoids in the1980s, justifying their action on the basis that sports personalities were role models and that the use of marijuana brought sport into disrepute. This was slightly different from their approach to alcohol, which was only screened at the request of the governing body when athlete safety was an issue. Individual sporting bodies have therefore had the option of whether to include cannabis and alcohol on their banned list. A sport in which both alcohol and cannabis are banned is skiing; originally their use was prohibited in the high risk disciplines ski jumping, downhill racing, and freestyle aerials.

\section{WHAT IS USED?}

A variety of recreational drugs are commonly used in society and have the potential for abuse by sportsmen and women. They include:

(1) IOC banned drugs

(a) Stimulants

- Amphetamines (including methamphetamine)

- Cocaine

- MDMA, MDA and MDEA (ecstasy-like drugs)

(b) Narcotic analgesics

- Opiates (heroin, morphine, pethidine)

(2) IOC monitored (not generally prohibited) drugs

- Cannabinoids

- Alcohol

(3) Substances that are not screened at all by the IOC

- LSD (lysergic acid diethylamide)

- PCP (phencyclidine)

- Ketamine

- Tiletamine

- Gamma hydroxybutyrate ("GHB")

Table 2 Positive drug test comparison 1993/1994 to 2000/2001: Anti-Doping Reports of UKSport (info@uksport.gov.uk)

\begin{tabular}{|c|c|c|c|c|c|c|c|c|c|c|}
\hline & $93 / 94$ & $94 / 95$ & $95 / 96$ & $96 / 97$ & $97 / 98$ & $98 / 99$ & $99 / 00$ & $00 / 01$ & Total & $\%$ \\
\hline \multicolumn{11}{|l|}{ Stimulants } \\
\hline Cocaine & 0 & 0 & 3 & 4 & 2 & 1 & 4 & 3 & 17 & 2.5 \\
\hline MDMA/MDEA & 1 & 3 & 1 & 2 & 0 & 0 & 3 & 5 & 15 & 2.2 \\
\hline Amphetamine & 2 & 4 & 4 & 0 & 5 & 0 & 1 & 4 & 20 & 2.9 \\
\hline Methamphetamine & 0 & 1 & 0 & 0 & 0 & 0 & 0 & 0 & 1 & 0.1 \\
\hline Other stimulants & 8 & 22 & 33 & 33 & 33 & 27 & 47 & 42 & 245 & 35.6 \\
\hline \multicolumn{11}{|l|}{ Narcotics } \\
\hline Morphine & 1 & 0 & 0 & 0 & 0 & 1 & 2 & 0 & 4 & 0.6 \\
\hline Other narcotics & 4 & 4 & 4 & 1 & 0 & 0 & 0 & 1 & 14 & 2.0 \\
\hline Anabolic agents & 21 & 23 & 15 & 27 & 13 & 20 & 33 & 22 & 174 & 25.3 \\
\hline Diuretics & 0 & 2 & 1 & 4 & 4 & 9 & 6 & 4 & 30 & 4.4 \\
\hline Peptide hormones & 2 & 0 & 0 & 1 & 0 & 0 & 3 & 2 & 8 & 1.2 \\
\hline Marijuana & 2 & 10 & 10 & 2 & 8 & 4 & 9 & 10 & 55 & 8.0 \\
\hline Alcohol & 1 & 0 & 3 & 2 & 0 & 0 & 4 & 3 & 13 & 1.9 \\
\hline$\beta$ Blockers & 0 & 1 & 0 & 0 & 0 & 1 & 0 & 3 & 5 & 0.7 \\
\hline Hypnotic sedatives & 0 & 0 & 0 & 1 & 0 & 0 & 1 & 0 & 2 & 0.3 \\
\hline Refusals & 6 & 8 & 15 & 13 & 14 & 13 & 6 & 11 & 86 & 12.5 \\
\hline Totals & 48 & 78 & 89 & 90 & 79 & 76 & 119 & 110 & 689 & 100.0 \\
\hline
\end{tabular}




\section{WHICH SPORTS ARE AT THE GREATEST RISK?}

In sports in which safety of the participants is a major issue, such as horse racing, motor racing, and motor cycle racing, the governing bodies are appropriately more concerned about any impairment of performance that could put the participant, and other competitors, at risk. Sports that provide the opportunity to earn high disposable incomes may also place participants in situations in which they are able to afford social drugs.

In this context, there is a good case to include all the recreational drugs listed as prohibited substances by governing bodies of high speed/high risk sports (including alcohol at an agreed threshold). One sport in which this has been pursued is horse racing.

\section{WHO USES DRUGS?}

Drug testing is part of elite sport and is one of the means by which adherence to drug codes is monitored. Table 1 shows the 12 year history of positive findings recorded in the United Kingdom from a total sample of over 50000 tests.

Table 2 shows a comparison of positive findings between 1993/1994 and 2000/ 2001. This includes both the major categories of banned drugs and some of the recreational drugs described above. This indicates that $18.2 \%$ of all positive results in the United Kingdom fall into the "social drugs" category, a figure that is only exceeded by other stimulants (35.6\%; predominantly cough and cold remedies) and anabolic agents (25.3\%). A significant management problem is whether an athlete who tests positive for a recreational drug should be treated the same as one who tests positive for a performance enhancing agent such as an anabolic steroid? Such sportspeople are plainly not "cheating" (in the performance sense) and a programme of counselling, rehabilitation, and monitoring would seem far more productive than a simplistic mandatory ban from sport. This lesson has been learnt by the professional sports: the Football Association (FA) introduced their social drug policy and programme in 1997, and The Lawn Tennis Association (LTA) introduced a similar scheme in 2000.

\section{SUMMARY}

There has been a worldwide increase in the use of recreational or social drugs, creating management problems for sports governing bodies and their medical advisers. It is recommended that they consider the use of a separate procedure for the management of positive findings of recreational drugs that recognises the highly addictive nature of these products and the fact that their consumption has nothing to do with performance enhancement or "cheating". Similarly, given that younger athletes are at greatest risk, a priority needs to be given to drug education in these groups. Preventive counselling for young players also highlights the problems for these at risk groups, and the means by which athletes can avoid high risk situations or be aware of the negative health effects of drug testing codes in their sport can be put forward. Monitoring would seem to be far more productive than the simplistic mandatory two year ban from sport required by the World Anti-Doping Agency for a first offence.

\section{Authors' affiliations}

M Turner, Lawn Tennis Association, The Queens Club, Palliser Road, London W14 9EG, UK

P McCrory, Centre for Sports Medicine Research \& Education and Brain Research Institute, University of Melbourne, Melbourne, Australia

Correspondence to: Dr Turner; jockeydoc@aol.com 